\title{
Preclinical analysis of the antitumor efficacy of TS-1 using human uterine cervical cancer tumor xenografts
}

\author{
NOBUTAKA NAGAI $^{1}$, MASAAKI KOMATSU $^{2}$, MAYU YUNOKAWA $^{2}$, YUKO SHIROYAMA $^{2}$ and EIJI HIRATA ${ }^{2}$ \\ ${ }^{1}$ Department of Obstetrics and Gynecology, Hiroshima City Asa Hospital; ${ }^{2}$ Department of Obstetrics and Gynecology, \\ Hiroshima University Graduate School of Biological Sciences, Hiroshima, Japan
}

Received February 22, 2008; Accepted May 20, 2008

DOI: 10.3892/or_00000123

\begin{abstract}
We investigated the antitumor activity of TS-1 in comparison with that of UFT and cisplatin (CDDP) against cervical cancer using xenografts of a human uterine cervical squamous cell cancer cell line, CaSki, transplanted into female Balb/cA JcL-nu mice. CaSki cell xenografts were prepared by subcutaneous (s.c.) implantation of $3 \times 10^{6}$ cells/animal into the right dorsal region of the mice. The tumor volume was measured twice a week and the relative tumor volume (RTV) was calculated. We divided the animals into four groups according to the treatment administered; TS $-1(10 \mathrm{mg} / \mathrm{kg}$ orally, once daily for 14 consecutive days), UFT $(24 \mathrm{mg} / \mathrm{kg}$ orally, once daily for 14 consecutive days), CDDP $(7.6 \mathrm{mg} / \mathrm{kg}$ injected intravenously once on the 1st day) and control (no treatment) groups. The antitumor effects of the drugs were measured. On the 35th day after the completion of treatment, the mean tumor volume in the mice treated with TS- 1 or CDDP changed from $132.873 \pm 11.783 \mathrm{~mm}^{3}$ to $706.401 \pm$ $613.122 \mathrm{~mm}^{3}$ and $133.809 \pm 19.366 \mathrm{~mm}^{3}$ to $722.630 \pm 855.509$ $\mathrm{mm}^{3}$, respectively. The mean tumor volume in the groups treated with TS-1 or CDDP was significantly lower compared to that in the control group $(\mathrm{p}<0.001$; one-tailed Student's t-test). The relative inhibition of the tumor growth was 65.31 in the TS-1 group, 48.31 in the UFT group and 64.51 in the CDDP group. We conclude that TS-1 administered orally for 14 consecutive days showed the highest antitumor activity.
\end{abstract}

Correspondence to: Dr Nobutaka Nagai, Department of Obstetrics and Gynecology, Hiroshima City Asa Hospital, 2-1-1, Kabe Minami, Asa Kita-ku, Hiroshima 731-0293, Japan

E-mail: n-nagai@asa-hosp.city.hiroshima.jp

Abbreviations: CDDP, cisplatin; RTV, relative tumor volume; RI, relative inhibition of tumor growth; NAC, neoadjuvant chemotherapy; 5-FU, 5-fluorouracil; FT, tegafur; TP, thymidine phosphorylase; DPD, dihydropyrimidine dehydrogenase; FBAL, F- 3 -alanine; CDHP, 5-chloro-2,4-dihydroxy-pyridine

Key words: TS-1, uterine cervical cancer, antitumor efficacy, preclinical study

\section{Introduction}

Treatment of advanced uterine cervical carcinoma has been mainly dependent on surgery and radiotherapy, however, recently improved efficacy of chemotherapy with multiple agents has been demonstrated (1-3) and its usefulness pointed out. As a result, chemotherapy has been administered not only as adjuvant therapy to surgery and radiotherapy, but also as neoadjuvant chemotherapy (NAC) before surgical treatment. 5-Fluorouracil (5-FU), an antitumor pyrimidine, has been frequently used clinically to treat patients with gastrointestinal, head and neck and uterine cancers. UFT is an oral fluoropyrimidine agent containing a masked form of 5-FU, prepared as a mixture of tegafur (FT) and uracil at a molar ratio of 1:4 (4). Conversion of tegafur to 5-FU is catalyzed by cytochrome $\mathrm{P}-450$ in the hepatic microsomes (CYP2A6) and thymidine phosphorylase (TP) in other tissues. Thereafter, UFT is converted to FdUMP or FUMP in the tumor cells and inhibits the synthesis of DNA and RNA. On the other hand, the half-life of 5-FU in the blood is short (6-20 min), because the compound is rapidly inactivated by hepatic or intracellular dihydropyrimidine dehydrogenase (DPD) and excreted in the urine as F- 3 -alanine (FBAL) (5). Thus, the activity of DPD is a major impediment to the maintenance of an effective concentration of 5-FU; however, the uracil moiety in UFT is a DPD-inhibitory fluoropyrimidine (6) that competitively inhibits DPD activity and suppresses the degradation of 5-FU, with a resultant increase in the plasma 5-FU level. Our previous study indicated that the tumor DPD activity in advanced cervical carcinoma is a determinant of the tumor sensitivity to UFT, suggesting an association between UFT therapy and the induction of apoptosis, and measurement of the tumor DPD activity before UFT therapy may possibly be used as an indicator of the tumor sensitivity to oral fluoropyrimidines (7).

TS-1 is a newly developed novel form of an FT-based antitumor agent (Fig. 1) consisting of $1 \mathrm{M} \mathrm{FT} \mathrm{(8),} \mathrm{a} \mathrm{pro-drug}$ of 5-FU, 0.4 M 5-chloro-2,4-dihydroxy-pyridine (CDHP) (9), a potent inhibitor of DPD and $1 \mathrm{M}$ potassium oxonate (Oxo) (10), an inhibitor of orotate phosphoribosyltransferase, which thereby acts as a protector against the gastrointestinal toxicity of 5-FU.

In this study, we investigated the antitumor activity of TS-1 in comparison with that of UFT and cisplatin (CDDP) against 
cervical cancer using xenografts of a human uterine cervical squamous cell cancer cell line, CaSki, transplanted into female Balb/cA JcL-nu mice.

\section{Materials and methods}

TS-1 and UFT were products of Taiho Phamaceutical Co., Ltd (Tokyo, Japan). CDDP was provided by Bristol-Myers Squibb Co., Ltd (Tokyo, Japan).

Animals and cancer cells. Five-week-old Balb/cA JcL-nu female mice were purchased from CLEA Japan Inc. (Tokyo, Japan). The mice were kept in laminar air-flow units throughout the period of the therapeutic experiments and fed a sterilized pellet diet and autoclaved water. The human cervical squamous cancer cell line, CaSki, was provided by the Health Science Research Resource Bank (Osaka, Japan).

The handling of animals were performed appropriately in accordance with 'Standards Relating to the Care and Management of Laboratory Animals and Relief of Pain (Notification No. 88, April 28, 2006 of the Prime Minister's Office)' and 'Guidelines on Methods of Sacrificing Laboratory Animals (Notification No.59, December 1, 2000 of the Ministry of Environment)'.

Antitumor experiments. In a preliminary experiment, we investigated the change in the tumor volume and implantation rate of CaSki cells in the mice by using $3 \times 10^{5}, 1 \times 10^{6}, 3 \times 10^{6}$ and $1 \times 10^{7}$ cells/animal, and based on the results, selected the cell density of $3 \times 10^{6}$ cell/animal, which showed the highest rate of tumor growth, for the implantation (Fig. 2). Table I shows the human cancer cell xenograft, the drugs and the treatment schedules used in this study. Human cancer cell xenografts were prepared by subcutaneous (s.c.) implantation of $3 \times 10^{6}$ cells/animal of the tumor cell line into the right dorsal region of the mice, which weighed $22.22 \pm 0.85-22.58-0.79 \mathrm{~g}$ at the time of the experiment.

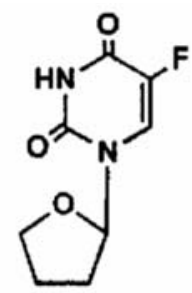

FT<smiles>Oc1cc(O)c(Cl)cn1</smiles>

CDHP<smiles>[R]OC(=O)c1nc(=O)[nH]c(=O)[nH]1</smiles>

Oxo
Figure 1. Chemical structure of TS-1. TS-1 consists of FT (Tegafur) as an effector of 5-FU and two modulators, CDHP (5-chloro-2,4-dihydroxypyridine) and Oxo (potassium oxonate).

The tumor volume $\left(\mathrm{mm}^{3}\right)$ [(major axis)x(minor axis)x 1/2] was measured twice a week throughout the experiment and the relative tumor volume (RTV) was calculated as RTV $=($ mean tumor volume during or after treatment)/(mean tumor volume at the start of the treatment).

We divided the mice into four treatment groups: the TS-1, UFT, CDDP and control groups. When the tumor volume in the tumor-bearing mice reached $130 \mathrm{~mm}^{3}$, we selected mice so that the average tumor volume in each treatment group was the same. Rationale for dose selection: to the tumor-bearing mice subcutaneously implanted with Sarcoma-180, Leis lung carcinoma, and colon 26 adenocarcinoma, TS-1 and UFT were administered once daily for 9 consecutive days, and the doses of 50\% tumor growth inhibition (ED50) was determined in the control groups. As the result, ED50 was 9.3 to $19.3 \mathrm{mg} / \mathrm{kg} /$ day for TS-1, and 24.1 to $34.8 \mathrm{mg} / \mathrm{kg} /$ day for UFT. Consequently, for the present study, 14-days oral administration was selected for TS-1 and for UFT, at the doses of $10 \mathrm{mg} / \mathrm{kg}$ /day for TS-1, and $24 \mathrm{mg} / \mathrm{kg} /$ day for UFT. For the nude mice implanted with UCC-8-JCK, uterine cervical cancer, a single dose of CDDP was intravenously injected at the dose of $7.6 \mathrm{mg} / \mathrm{kg}, 1 / 2$ quantity of LD50 value of CDDP. As a result, relative

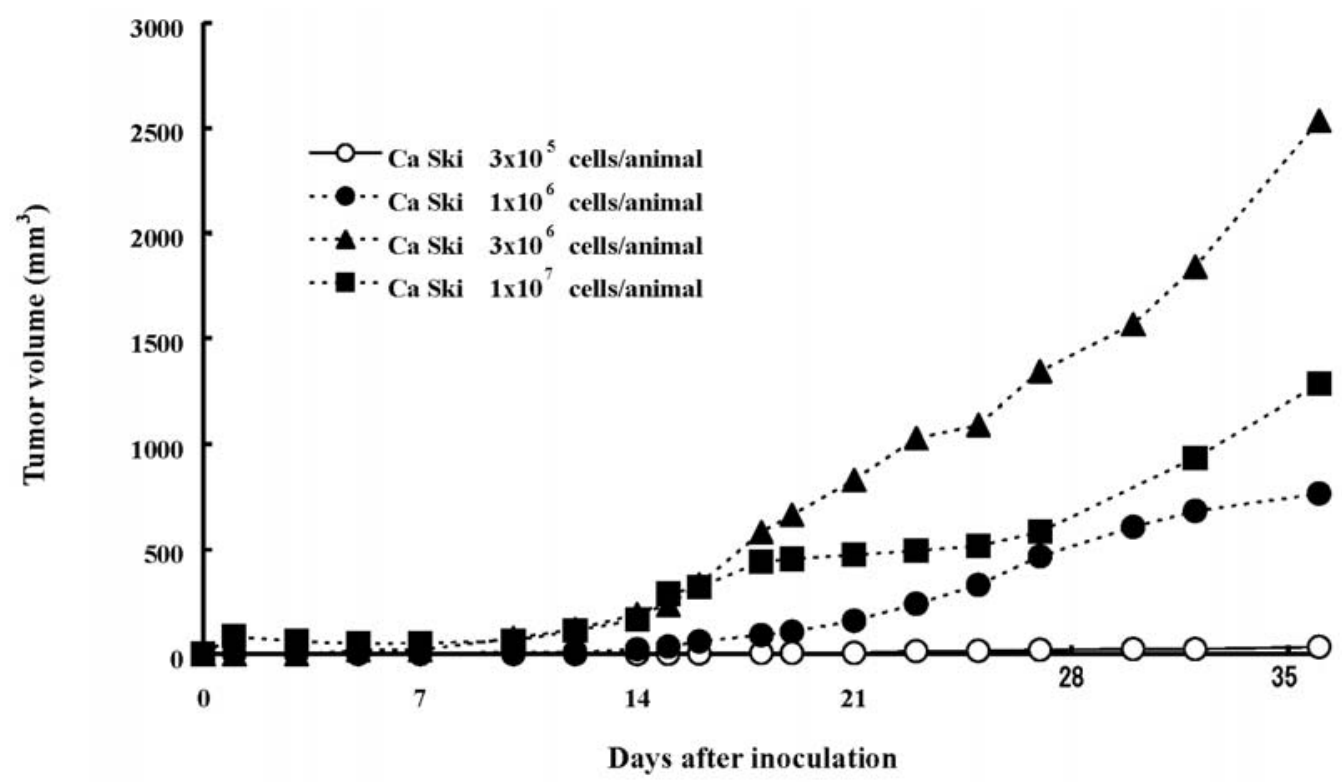

Figure 2. Changes in the tumor volume in the CaSki-tumor-bearing mice. Each point represents the mean value of the tumor volume. The experiment was replicated five or six times. 


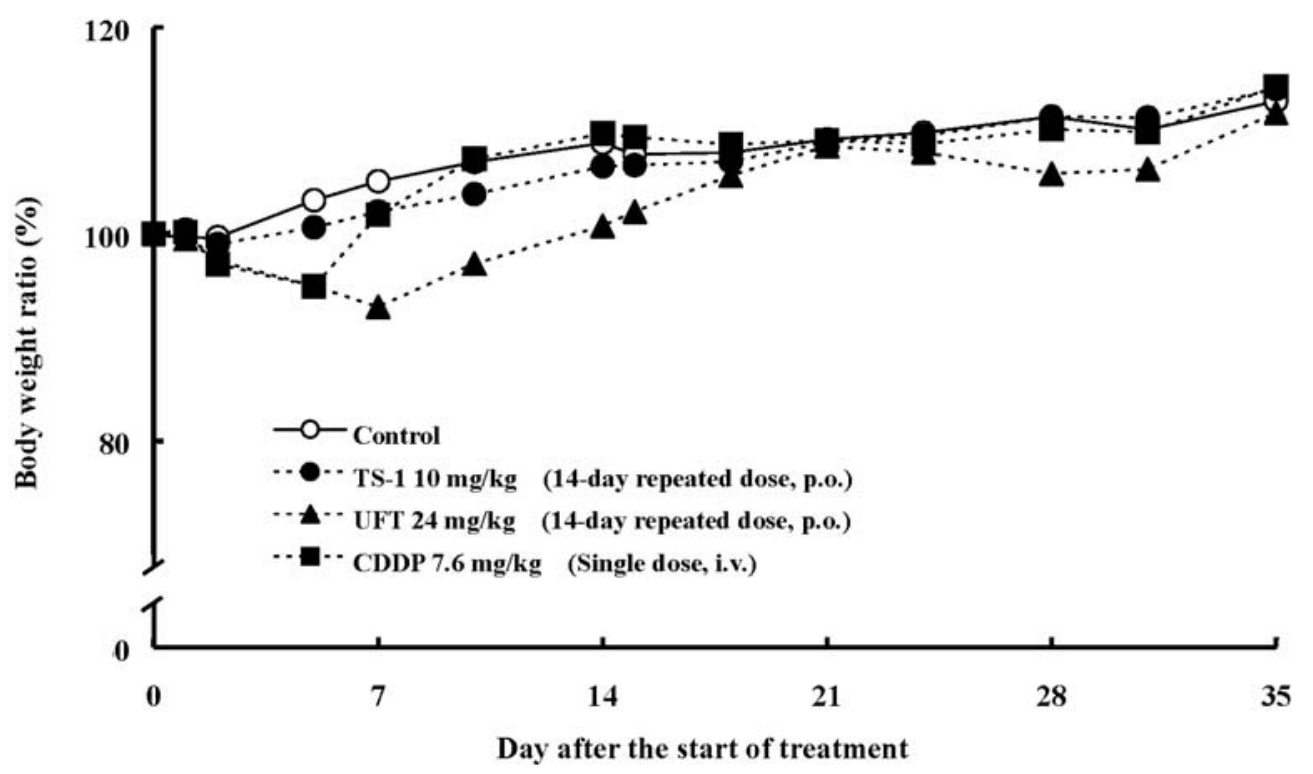

Figure 3. Body weight ratio of the CaSki-tumor-bearing mice treated with TS-1, UFT and CDDP. Each point represents the mean value of the body weight ratio. The experiment was replicated ten times. CDDP, cisplatin.

Table I. Animal, tumor and treatment schedules.

\begin{tabular}{lccccc}
\hline Animal & Cell line & Tumor type & Drug & Dose (mg/kg) & Schedule \\
\hline Nude mice & CaSki & Uterine & TS-1 & 10 & Daily x 14 (oral) \\
& & Cervix & UFT & 24 & Daily x 14 (oral) \\
& & CDDP & 7.6 & Day 1st (i.v.) \\
\hline
\end{tabular}

CDDP, Cisplatin and i.v., intravenous.

inhibition of tumor growth was $61 \%$. Consequently, for the present study, a single dose intravenous administration at the dose of $7.6 \mathrm{mg} / \mathrm{kg}$ was selected for CDDP.

The day the drug administration commenced was designated as the 1 st day. TS- $110 \mathrm{mg} / \mathrm{kg}$ and UFT $24 \mathrm{mg} / \mathrm{kg}$ were administered orally once daily for 14 consecutive days via the feeding tube. CDDP was injected intravenously at the dose of $7.6 \mathrm{mg} / \mathrm{kg}$ once on the 1 st day (Table I). The drugs were administered to the mice for 14 days starting at 14-20 days after the tumor implantation. The antitumor effect of the drugs was measured using the following equation: relative inhibition of tumor growth $(\mathrm{RI}, \%)=[1-($ mean RTV in the drug-treated group/mean RTV in the control group)]x100.

We observed the general appearance and activity and checked on the general condition of the CaSki-tumor-bearing mice more than once a day before, during and after the drug administration. The body weight of the CaSki-tumorbearing mice was measured before the start of treatment, on the 1st, 2nd, 5th, 10th and 14th day (during the treatment), and on the 15 th, 18th, 21st, 24th, 31st and 35th day (after the completion of treatment). Host weight was calculated as the body weight minus the tumor volume. The body weight ratio (\%) was calculated as follows: Body weight ratio = (body weight during or after completion of treatment/body weight before the start of treatment)x 100 .
Statistical analysis. The significance of differences between the animal groups and/or drugs was assessed using one-tailed Student's t-test or the one-tailed Aspin-Welch t-test.

\section{Results}

In this experiment, no significant differences in the body weight change or host weight change in the CaSki-tumorbearing mice were noted among the TS-1, UFT, CDDP and control groups.

Tables IIA and IIB show the general appearance of the CaSki-tumor-bearing mice treated with TS-1, UFT or CDDP and the control group. As compared with the mice in the control group and the TS-1-treated group, the animals treated with UFT or CDDP suffered from pasty or soft stools from the 2 nd to the 18 th day. In the group treated with UFT as compared with the other groups, the body weight ratio was significantly decreased from the 8 th to the 14 th day $(\mathrm{P}<0.01)$, to increase gradually thereafter (Fig. 3). Only one mouse, which had received CDDP, died on the 34th day (after completion of treatment).

Fig. 4 shows the tumor volumes $\left(\mathrm{mm}^{3}\right)$ in the CaSki-tumorbearing mice treated with TS-1, UFT or CDDP and the control group. Each point represents the mean value of the tumor volume. On the 35 th day (after completion of treatment), 


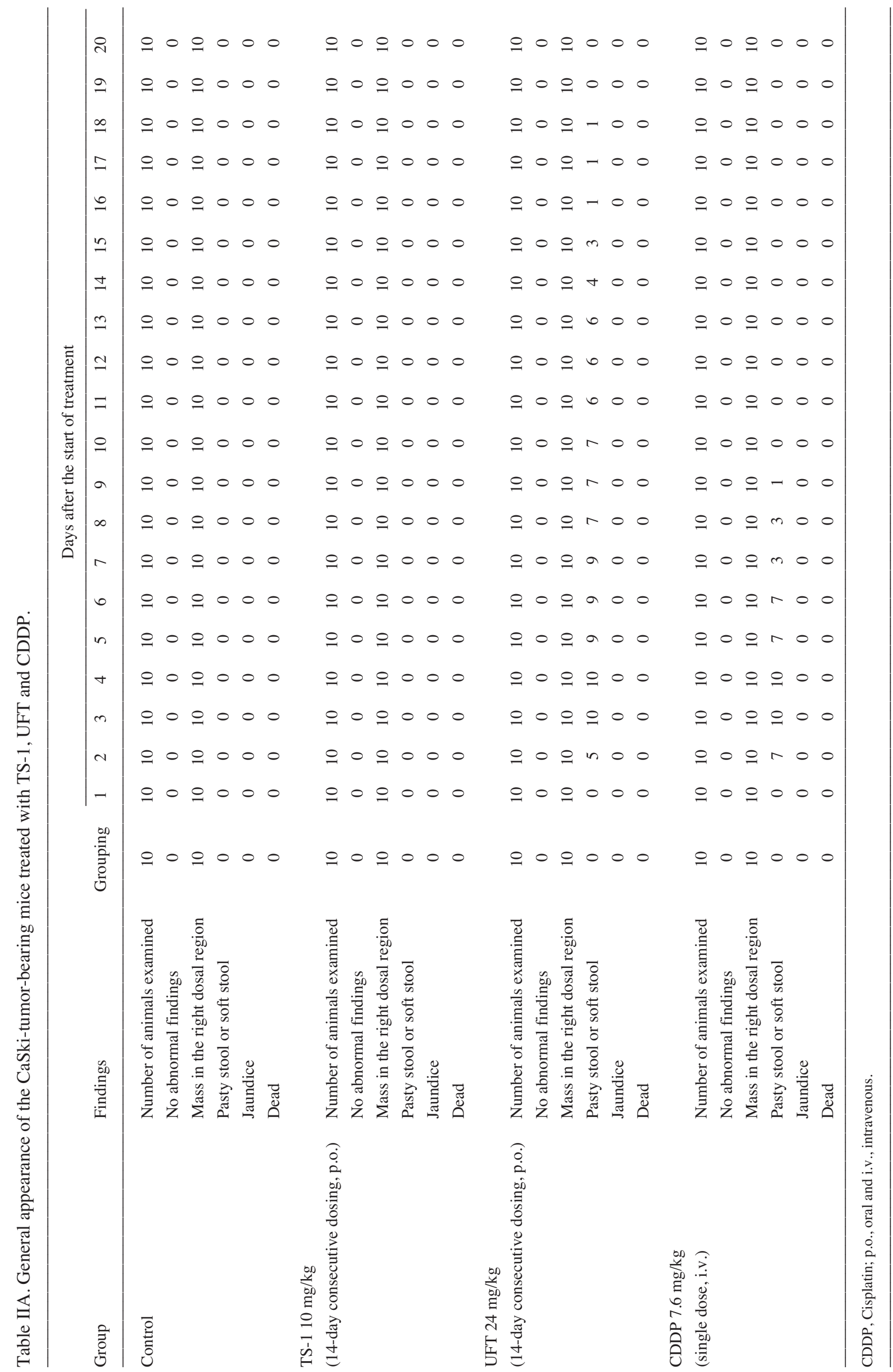




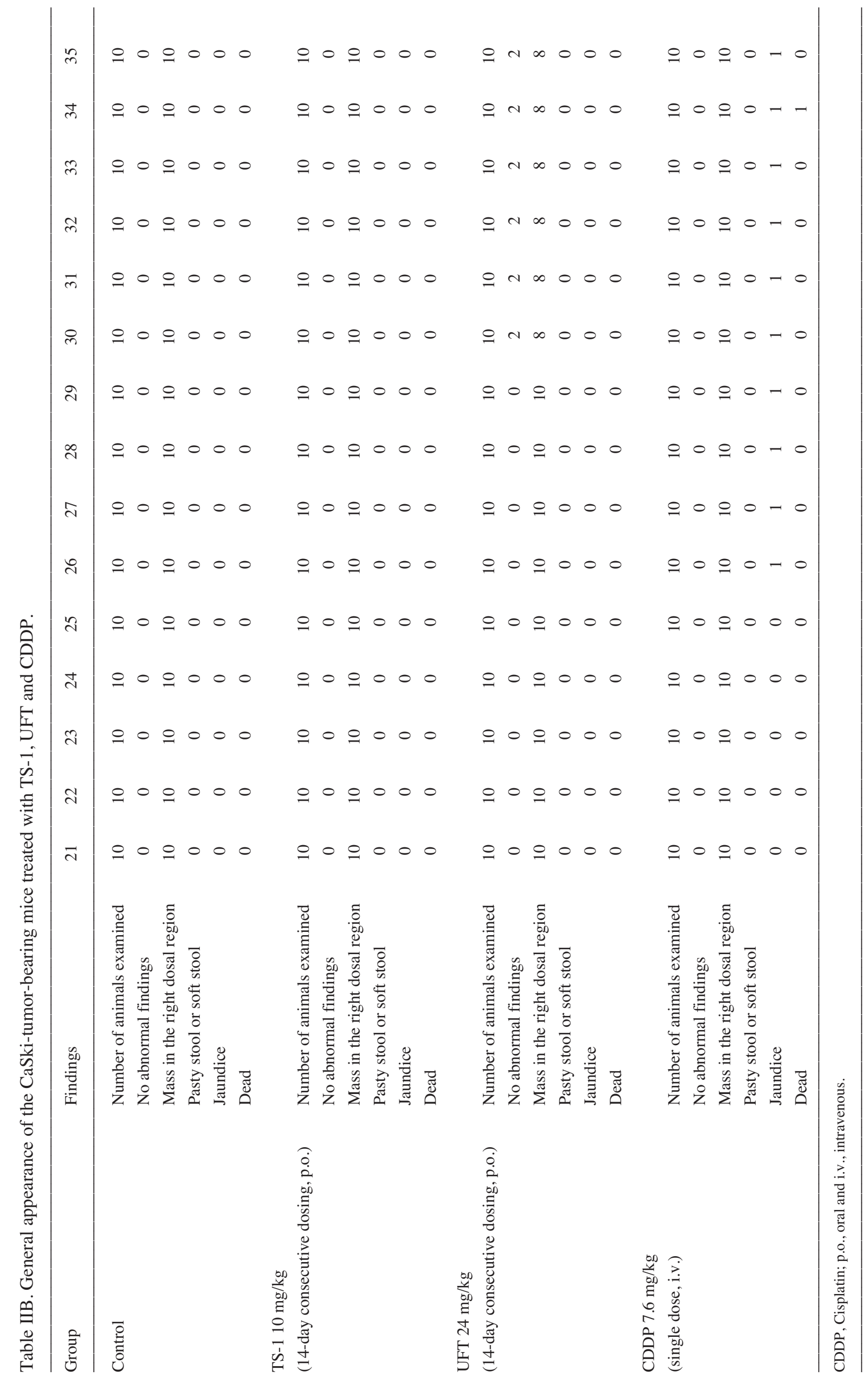




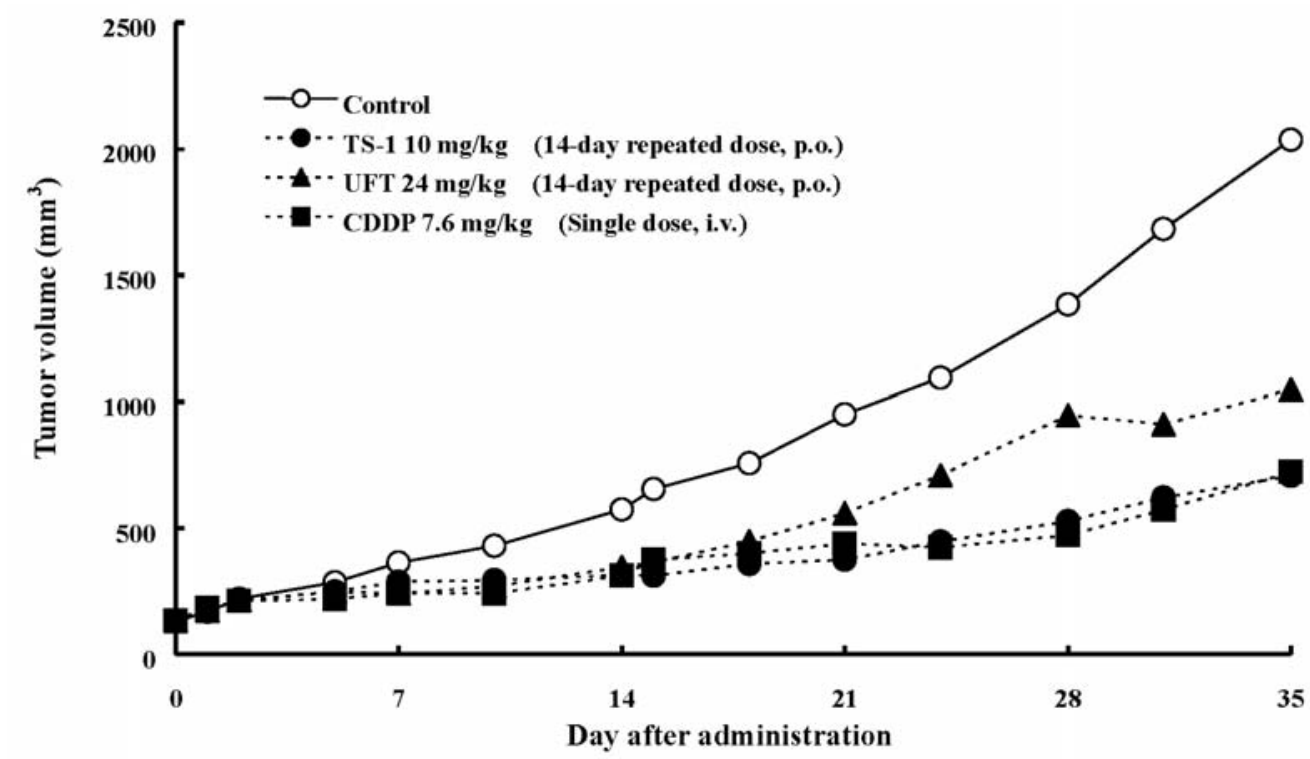

Figure 4. Tumor volume in the CaSki-tumor-bearing mice treated with TS-1, UFT and CDDP. Each point represents the mean value of the tumor volume. The experiment was replicated ten times. CDDP, cisplatin.
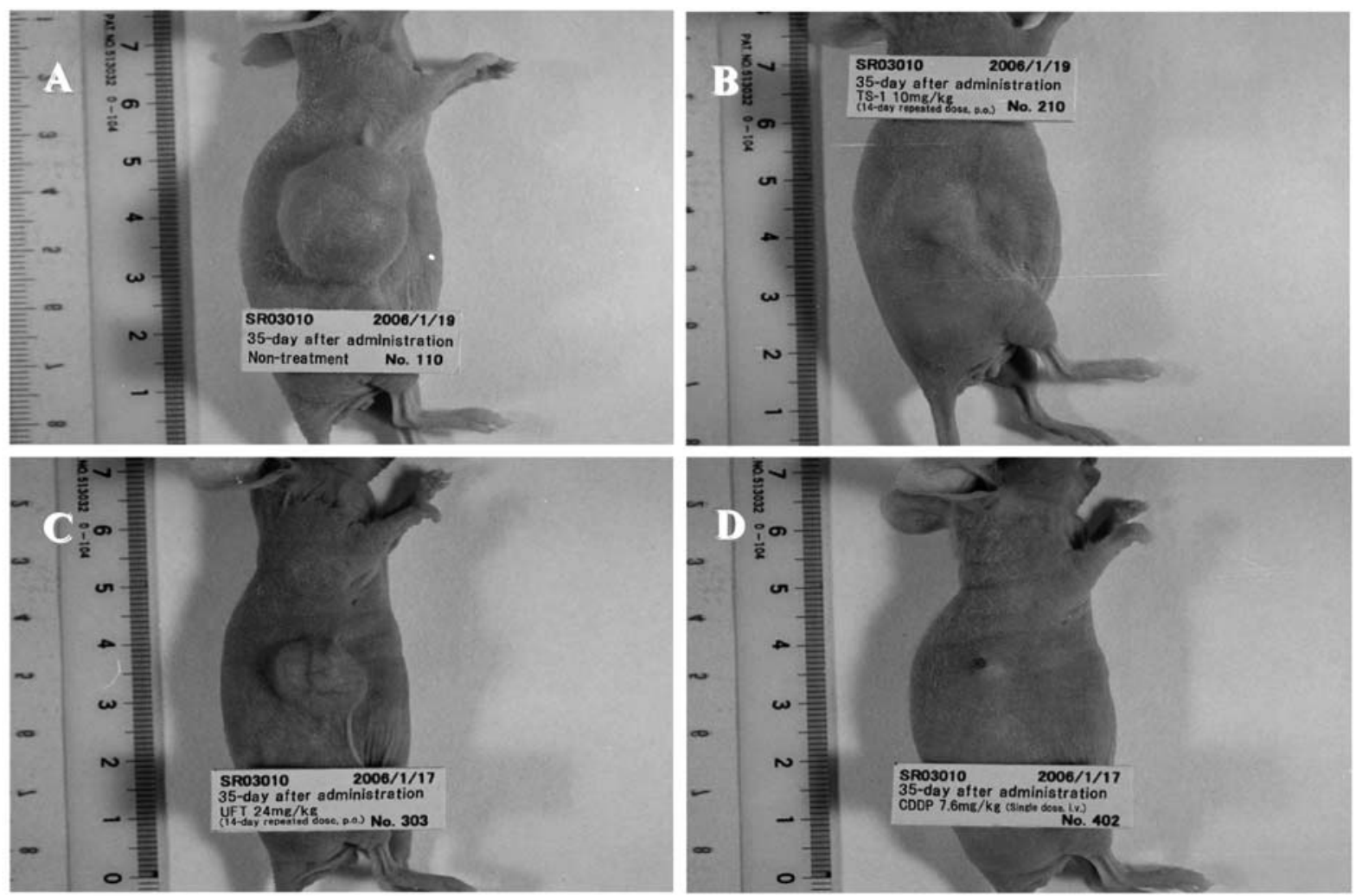

Figure 5. The external appearance of mice with tumor. (A) Thirty-fifth day (after completion of treatment). Control. Animal no. 110; (B) 35th day (after completion of treatment). TS-1 $10 \mathrm{mg} / \mathrm{kg}$ (14-day consecutive dosing, p.o.). Animal no. 210; (C) 35th day (after completion of treatment). UFT $24 \mathrm{mg} / \mathrm{kg}$ (14-day consecutive dosing, p.o.). Animal no. 303; (D) 35th day (after completion of treatment). CDDP $7.6 \mathrm{mg} / \mathrm{kg}$ (single dose, i.v.). Animal no. 402.

the mean tumor volume in the mice treated with TS-1 or CDDP had increased from $132.873 \pm 11.783 \mathrm{~mm}^{3}$ to $706.401 \pm 613.122 \mathrm{~mm}^{3}$ and $133.809 \pm 19.366 \mathrm{~mm}^{3}$ to $722.630 \pm 855.509 \mathrm{~mm}^{3}$, respectively. Thus, on the 35 th day (after treatment completion), the mean tumor volume in the groups treated with TS-1 or CDDP was significantly lower as compared with that in the control group $(\mathrm{P}<0.001$; one-tailed
Student's t-test). The mean tumor volume in the mice treated with UFT was also lower than that in the control group $(\mathrm{P}<0.005$; one-tailed Student's t-test) (Fig. 5).

Table III shows that relative inhibition of the tumor growth among the groups treated with TS-1, UFT and CDDP. On the 35th day (after treatment completion), the relative inhibition of tumor growth was 65.31 in the TS-1 group, 48.31 in the UFT 
group and 64.51 , in the CDDP group. From the above results, it was concluded that TS-1 administered orally for 14 consecutive days yielded the best antitumor activity.

\section{Discussion}

One of the important disadvantages of 5-FU is its rapid degradation in vitro catalyzed by the liver DPD. Our previous study indicated that the tumor DPD activity is a determinant of the tumor sensitivity to 5-FU in uterine cervical cancer, and the tumor DPD activity measured prior to the start of treatment may be used as an indicator of the sensitivity to oral fluoropyrimidines (7).

The uracil moiety in UFT is a DPD-inhibitory fluoropyrimidine (6), which competitively inhibits DPD activity and suppresses the degradation of 5-FU, with a resultant increase of the plasma 5-FU level. The response rate of advanced cervical carcinoma to UFT alone has been reported to be $16.0 \%(4 / 25)$. In regard to the relationship of the tumor histology on the tumor sensitivity to chemotherapeutic agents, it has been reported that the response rate is $16.7 \%$ in patients with large-cell non-keratinized squamous cell carcinoma (12).

UFT has long been used for adjuvant chemotherapy in patients undergoing surgery and radiotherapy. Studies including a multicenter trial in Japan have shown that the addition of UFT can significantly improve the disease-free survival in patients receiving radiotherapy (13), indicating that it may also have a recurrence-preventing effect.

The novel oral fluoropyrimidine TS-1 was developed as a mixture of FT, CDHP, a potent and reversible inhibitor of DPD, and Oxo, which characteristically protects against the gastrointestinal toxicity of 5-FU (11). As a result, high plasma 5-FU levels are maintained for a prolonged period of time after oral administration of TS- 1 to yield potent antitumor activity with low gastrointestinal toxicity in experimental murine tumor models $(14,15)$.

In this study, we investigated the antitumor activity of TS-1 against the human cervical squamous cell cancer cell line, Caski, xenografts transplanted into female Balb/cA JcL-nu mice to predict its clinical efficacy in comparison with that of UFT and CDDP. TS-1 showed excellent antitumor activity against the human cervical cancer cells as compared with that of UFT and nearly equivalent anti-tumor activity to that of CDDP. Although we did not investigate the pharmacokinetic behavior of TS-1, UFT or CDDP in this experiment, we speculate that the prolonged retention of 5-FU in the blood is related to the potent antitumor activity of the drug $(16,17)$ as compared with that of UFT (Table III).

In one clinical investigation, TS-1 showed excellent antitumor activity against stomach $(17,18)$, colorectal (19), breast (20), lung (21) and head and neck cancers (22), with response rates of $44-49,35.5,42.0,22.0$ and $28.8 \%$, respectively. Thus, the addition of chemotherapy in the treatment of advanced cervical cancer has improved the survival by controlling both the primary lesion and the distant metastases. Previously, neoadjuvant chemotherapy with a platinum-based regimen for operable cervical cancer yielded high response rates, ranging from 40 to $82 \%$ (23-25). In this experiment, the antitumor activity of TS-1 was excellent, and 
the relative inhibition of tumor growth in the CaSki-tumorbearing mice was equal to or greater than that obtained with CDDP.

We, therefore, conclude that TS-1 may be an effective agent both for adjuvant chemotherapy and neoadjuvant chemotherapy in cases of advanced uterine cervical cancer.

\section{Acknowledgements}

The authors thank Mr. Masao Kiguchi (Safety Research Institute for Chemical Compounds Co., Ltd.) and Taiho Phamaceutical Co., Ltd, Japan for their kind cooperation.

\section{References}

1. Lahousen M, Pickel H and Tamussino K: Chemotherapy for advanced and/or recurrent cervical cancer. Arch Gynecol 240: 247-252, 1987.

2. Alberts DS, Kronmal R, Baker LH, Stock-Novack DL, Surwit EA, Boutselis JG and Hannigan EV: Phase II randomized trial of cisplatin chemotherapy regimens in the treatment of recurrent or metastatic squamous cell cancer of the cervix: a Southwest Oncology Group Study. J Clin Oncol 5: 1791-1795, 1987.

3. Hirabayashi K and Okada E: Combination chemotherapy with 254-S, ifosfamide, and peplomycin for advanced or recurrent cervical cancer. Cancer 71: 2769-2775, 1993.

4. Fujii S, Ikenaka K, Fukushima M and Shirasaka T: Effect of uracil and its derivatives on antitumor activity of 5-fluorouracil and 1-(2-tetrahydrofuryl)-5-fluorouracil. Gann 69: 763-772, 1978.

5. Cohen JL, Irwin LE, Marshall GJ, Darvey H and Bateman JR: Clinical pharmacology of oral and intravenous 5-fluorouracil (NSC-19893). Cancer Chemother Rep 58: 723-731, 1974.

6. Chung YS, Yamashita Y, Inoue T, Matsuoka T, Nakata B, Onoda N, Maeda K, Sawada T, Kato Y, Shirasaka T and Sowa M: Continuous infusion of 5-fluorouracil and low dose cisplatin infusion for the treatment of advanced and recurrent gastric adenocarcinoma. Cancer 80: 1-7, 1997.

7. Nagai N, Shiroyama Y, Oshita T, Mukai K, Shigemasa K, Fujii T, Katsube Y, Matsubayashi S, Murakami T and Ohama K: Tumor dihydropyrimidine dehydrogenase activity in advanced cervical carcinoma. Oncol Rep 9: 1033-1040, 2002.

8. Hiller SA, Zhuk PA and Lidak MJ: Analog of pyromidine nucleosides, I. N-(a-furanidyl) derivatives of natural pyrimidine bases and their antimetabolities. Dokl Akad Kauk SSSR 176: 332-335, 1967.

9. Tatsumi K, Fukushima M, Shirasaka T and Fujii S: Inhibitory effects of pyrimidine, barbituric acid and pyridine derivatives on 5 -fluorouracil degradation in rat liver extracts. Jpn J Cancer Res 78: 748-755, 1987.

10. Shirasaka T, Shimamoto Y and Fukushima M: Inhibition by oxonic acid of gastrointestinal toxicity of 5-fluorouracil without loss of its antitumor activity in rats. Cancer Res 53: 4004-4009, 1993.

11. Fukushima M, Satake H, Uchida J, Shimamoto Y, Kato T, Takechi T, Okabe H, Fujioka A, Nakano K, Ohshimo H, Takeda S and Shirasaka T: Preclinical antitumor efficacy of S-1: a new oral formulation of 5-fluorouracil on human tumor xenografts. Int J
Oncol 13: 693-698, 1998

12. Noda K, Teshima K, Ikeda M, Sugawa T, Yamagata S, Sekiba K, Kohno I, Kaneshige E, Sawaragi I, Matsuoka I, et al: Phase II study of UFT in cancer of the uterine cervix. Gan To Kagaku Ryoho 12: 900-906, 1985.

13. Takeshima N, Hirai Y, Umezawa S, Katase K, Kato T, Shimizu Y, Chen JT and Yamauchi K: Adjuvant chemotherapy with oral administraion of UFT for carcinoma of the uterine cervix. J Jpn Soc Cancer Ther 31: 297-304, 1996.

14. Shirasaka T, Shimamato Y, Ohshimo H, Yamaguchi M, Kato T, Yonekura $\mathrm{K}$ and Fukushima M: Development of a novel form of an oral 5-fluorouracil derivative (S-1) directed to the potentiation of the tumor selective cytotoxicity of 5-fluorouracil by two biochemical modulators. Anticancer Drugs 7: 548-557, 1996

15. Takechi T, Nakano K, Uchida J, Mita A, Toko K, Takeda S, Unemi $\mathrm{N}$ and Shirasaka T: Antitumor activity and low intestinal toxicity of S-1, a new formulation of oral tegafur, in experimental tumor models in rats. Cancer Chemother Pharmacol 39: 205-211, 1997.

16. Drewinko B and Yang LY: Cellular basis for the inefficacy of 5-FU in human colon carcinoma. Cancer Treat Rep 69: 1391-1398, 1985.

17. Fujii S, Shimamoto Y, Ohshimo H, Imaoka T, Motoyama M, Fukushima $M$ and Shirasaka T: Effects of the plasma concentration of 5-fluorouracil and the duration of continuous venous infusion of 5-fluorouracil with an inhibitor of 5-fluorouracil degradation on Yoshida sarcomas in rats. Jpn J Cancer Res 80: 167-172, 1989.

18. Koizumi W, Kurihara M, Nakano S and Hasegawa K: Phase II study of S-1, a novel oral derivative of 5-fluorouracil, in advanced gastric cancer. For the S-1 Cooperative Gastric Cancer Study Group. Oncology 58: 191-197, 2000.

19. Ohtsu A, Baba H, Sakata Y, Mitachi Y, Horikoshi N, Sugimachi K and Taguchi T: Phase II study of S-1, a novel oral fluorophyrimidine derivative, in patients with metastatic colorectal carcinoma. S-1 Cooperative Colorectal Carcinoma Study Group. Br J Cancer 83: 141-145, 2000.

20. Saeki T, Takashima S, Sano M, Horikoshi N, Miura S, Shimizu S, Morimoto K, Kimura M and Taguchi T: A late phase II clinical study of S-1 in patients with progressed, refractory breast cancer. Gan To Kagaku Ryoho 31: 539-547, 2004.

21. Kawahara M, Furuse K, Segawa Y, Yoshimori K, Matsui K, Kudoh S, Hasegawa K and Niitani H: Phase II study of S-1, a novel oral fluorouracil, in advanced non-small-cell lung cancer. Br J Cancer 85: 939-943, 2001.

22. Inuyama Y, Kida A, Tsukuda M, Kohno N and Satake B: Late phase II study of S-1 in patients with advanced head and neck cancer. Gan To Kagaku Ryoho 28: 1381-1390, 2001.

23. Sueyama H, Nakano M, Sakumoto K, Toita T, Takizawa Y, Moromizato H, Kakihana Y, Kushi A, Higashi M, et al: Intraarterial chemotherapy with cisplatin followed by radical radiotherapy for locally advanced cervical cancer. Gynecol Oncol 59: 327-332, 1995.

24. Sugiyama T, Nishida T, Hasuo Y, Fujiyoshi K and Yakushiji M: Neoadjuvant intraarterial chemotherapy followed by radical hysterectomy and/or radiotherapy for locally advanced cervical cancer. Gynecol Oncol 69: 130-136, 1998.

25. Kobayashi K, Furukawa A, Takahashi M and Murata K: Neoadjuvant intra-arterial chemotherapy for locally advanced uterine cervical cancer: clinical efficacy and factors influencing response. Cardiovasc Intervent Radiol 26: 234-241, 2003. 